\title{
Hemoglobin correction factors for estimating the prevalence of iron deficiency anemia in pregnant women residing at high altitudes in Bolivia
}

\author{
Jennifer Hadary Cohen ${ }^{1}$ and Jere D. Haas ${ }^{1}$
}

\begin{abstract}
This study had two primary objectives: 1) to derive a method to determine hemoglobin cutoffs that could be used to better estimate the prevalence of iron deficiency anemia in pregnancy at high altitudes and 2) to estimate the prevalence of anemia in a sample of pregnant women residing in two cities in Bolivia, La Paz (3 600 meters) and El Alto (4 000 meters). We derived a hemoglobin-altitude curve from previously published data on the mean hemoglobin concentrations of nonanemic women of childbearing age at various altitudes. In addition, we abstracted data on hemoglobin concentration during pregnancy from medical records of women from $\mathrm{La}$ Paz and El Alto who had given birth at a maternity hospital in La Paz between January and June of 1996. Using our approach and two other previously published, currently used methods, we calculated and compared prevalences of iron deficiency anemia in this population using hemoglobin cutoffs determined from a hemoglobin-altitude curve corrected for pregnancy.

The hemoglobin-altitude curve derived in this study provided a better fit to data for women of childbearing age than the two other models. Those models used cutoffs based on non-ironreplete populations of children or men, both of which were residing below $4000 \mathrm{~m}$, and then extrapolated to women and higher altitudes. The estimated prevalences of iron deficiency anemia in pregnancy using the hemoglobin cutoffs determined in this study were higher than those estimated by the two other approaches.
\end{abstract}

Iron deficiency anemia is a welldocumented problem during pregnancy and at other times for women of childbearing age in both developed and developing countries. The worldwide prevalence of iron deficiency among women of childbearing age is estimated to be around $50 \%(1-3)$, and

\footnotetext{
1 Cornell University, Division of Nutritional Sciences, Ithaca, New York, United States of America. Send correspondence to: Jennifer Hadary Cohen, Fred Hutchinson Cancer Research Center, 1100 Fairview Ave N., MP 702, Seattle, Washington 98109-1024. E-mail: jcohen@fhcrc.org
}

estimates for developing countries range from $40 \%$ to $88 \%$ (3). Iron deficiency anemia in pregnancy is generally due to the already low levels of body iron stores women have entering pregnancy, combined with the expansion of the maternal red blood cell mass and the growing fetus's increased demands for iron (4). The consequences of iron deficiency anemia in women include decreased work capacity, decreased ability to care for children, increased maternal morbidity and mortality, and poor infant and maternal outcomes of pregnancy (4).
The prevalence of iron deficiency anemia is often estimated in order to help make policy and programmatic decisions. The Pan American Health Organization recommends rapid assessment studies to obtain the minimum baseline information for these purposes rather than "sophisticated or expensive research projects to construct baseline information" (5). The most commonly used inexpensive and available method for estimating the prevalence of iron deficiency anemia is the hemoglobin cutoff method. Persons who fall below a set cutoff, often 
the 5th percentile of the nonanemic or normative distribution, are considered to be anemic (6). This hemoglobin indicator can provide useful baseline information for a population where iron deficiency is the predominant cause of anemia.

To estimate the prevalence of iron deficiency anemia, it is necessary to determine an appropriate hemoglobin cutoff. Factors which influence the selection of a cutoff include such physiological and environmental processes as pregnancy and altitude, which both affect hemoglobin concentration (4, 7-11). To account for normal plasma volume expansion in pregnancy, the World Health Organization (WHO) recommends that the sea-level hemoglobin cutoff of $120 \mathrm{~g} / \mathrm{L}$ for nonpregnant women be lowered to a level of $110 \mathrm{~g} / \mathrm{L}$ (4).

At high altitudes, hemoglobin concentration increases as an adaptive response to the lowered partial pressure of oxygen. However, currently used hemoglobin correction factors are problematic for estimating the prevalence of iron deficiency anemia in pregnancy at extreme high altitudes (above $3600 \mathrm{~m}$ ), where approximately 20 million people reside worldwide (8). The existing cutoffs have a variety of shortcomings, including being based on non-iron-replete children and men, relying on very few observations over critical altitudes, assuming that the relationship between hemoglobin concentration and altitude is linear throughout the range of altitudes and/or that the relationship also exists at lower altitudes, and being extrapolated to altitudes beyond which they have data $(7-9,12-14)$.

We propose a method to determine altitude-specific hemoglobin cutoffs based on an exponential curve of hemoglobin concentration by altitude. This model can be used to estimate the prevalence of iron deficiency anemia in women of childbearing age, including during pregnancy, at altitudes up to $4800 \mathrm{~m}$. We apply the method to a population of pregnant women residing in two cities in Bolivia, La Paz $(3600 \mathrm{~m})$ and El Alto $(4000 \mathrm{~m})$, and then compare our estimates of preva- lence with those obtained using the currently used hemoglobin correction methods of Dirren et al. (12) and Dallman et al. (13).

\section{MATERIALS AND METHODS}

We used previously published data $(7,8,15)$ on the mean hemoglobin concentrations of nonanemic women of childbearing age at various altitudes to fit the curve of hemoglobin concentration by altitude. The data we used are shown in Table 1.

We used the nonlinear least squares Levenberg-Marquardt curve-fitting procedure (16) to model the relationship between altitude and mean hemoglobin concentration in the ironreplete or -sufficient populations. We used the coefficient of determination $\left(R^{2}\right)$ values to determine the curve which best fit the data.

For comparison, we later fit our new curve to data from Dirren et al. (12) for Ecuadorian children between 800 and $3200 \mathrm{~m}$. We truncated the range of altitude in the data from Dirren et al. because we found a lack of biological or statistical evidence for any relationship between hemoglobin concentration and altitude below $1000 \mathrm{~m}$. We shifted our curve for women of childbearing age downward to account for the lower hemoglobin concentration of children.

We also fit the curve derived by Dirren et al., adjusted for the higher hemoglobin concentration of women at sea level, to the data of women of childbearing age and compared its fit to the fit of the curve derived in this study.
We determined the mean hemoglobin concentration of the iron-sufficient population at sea level using a sample of nonpregnant women of childbearing age from the Third National Health and Nutrition Survey (15), which had been conducted in the United States of America. That survey defined iron sufficiency by the ferritin method, which is based on two out of three laboratory tests of iron status being normal. Given the lack of evidence to the contrary, we assumed that the mean hemoglobin concentration of the iron-sufficient population at sea level was not significantly different from that at $1000 \mathrm{~m}$.

We derived the mean hemoglobin concentration for $2800 \mathrm{~m}$ from a study by Yepez et al. in Ecuador (7). That study investigated the frequency distribution of hemoglobin concentration in a population of nonpregnant women who received iron supplements.

We derived the mean hemoglobin concentrations for 3600 and $4800 \mathrm{~m}$ from experimental treatment trials by Berger et al. (8) showing hemoglobin response to iron supplementation among nonpregnant women in Atocha and Santa Barbara, Bolivia. Their study excluded polycythemics.

Using the four data points from 1000 to $4800 \mathrm{~m}$, we fit an exponential curve with the form:

$$
\begin{gathered}
\text { Hemoglobin }(\mathrm{g} / \mathrm{L})= \\
\mathrm{a} \times\left[\exp ^{(\mathrm{b} \times \text { (altitude-1000) }}\right]+\mathrm{c}
\end{gathered}
$$

In the equation, "a," "b," and "c" are constants calculated in the regression.

We fit the curve with a multiplicative error term because we assumed

TABLE 1. Hemoglobin concentration data for nonanemic women of childbearing age used to construct new hemoglobin-altitude curve, 1999

\begin{tabular}{llcrrc}
\hline Source of data & \multicolumn{1}{c}{$\begin{array}{c}\text { Population } \\
\text { location }\end{array}$} & Altitude $(\mathrm{m})$ & $\begin{array}{c}\text { Sample } \\
\text { size }\end{array}$ & $\begin{array}{c}\text { Mean } \\
(\mathrm{g} / \mathrm{L})\end{array}$ & $\begin{array}{c}\text { Standard } \\
\text { deviation }\end{array}$ \\
\hline Looker et al. (15) & United States of Americas & 1 $000 \sim$ sea level & \\
Yepez et al. (7) & Quito, Ecuador & 2800 & 399 & 134.8 & 8.2 \\
Berger et al. (8) & Atocha, Bolivia & 3600 & 65 & 163.0 & 7.0 \\
Berger et al. (8) & Santa Barbara, Bolivia & 4800 & 65 & 187.7 & 12.0 \\
& & & & & 13.7 \\
\hline
\end{tabular}

a No distinction is made between sea level and an altitude of $1000 \mathrm{~m}$ because of a lack of evidence to support a relationship between altitude and hemoglobin concentration below $1000 \mathrm{~m}$. 
that the coefficient of variation of hemoglobin concentration was constant across altitudes.

We used our and the two other altitude correction factors to estimate the prevalence of iron deficiency anemia during pregnancy for a sample of women 18-35 years old who gave birth between January and June of 1996 at the 18th of May Maternity Hospital in LaPaz, Bolivia. The retrospective crosssectional analysis included women residing in La Paz (3 $600 \mathrm{~m}$ ), as well as women residing in El Alto $(4000 \mathrm{~m})$, which is about a 30-minute bus ride from the maternity hospital.

Our study abstracted information from the women's hospital medical records. During pregnancy the women had presented for prenatal care at one of eight health clinics, in either La Paz or El Alto. The women first presented at the clinics anywhere between week 2 and week 32 of pregnancy, determined through recall of their last menstrual period. At the first such visit, each woman's hemoglobin concentration was assessed. Clinic staff members also conducted interviews to gather other data on each woman, including her education, parity, household income, and access to running water and electricity. At the time of delivery, the clinics transferred the medical records to the 18th of May Hospital.

Three hundred and twenty hemoglobin values were abstracted from the women's medical records. Of the 320 records, 2 were excluded because they were twin births and 15 were excluded because of documented pathologies, including preeclampsia, eclampsia, hemorraghia, premature labor, and urinary tract infection. The resulting 303 women included 101 from El Alto and 202 living in La Paz. To account for plasma volume expansion which normally occurs after the first trimester of pregnancy, we further separated the sample by the gestation period at the time when a woman first came to a clinic, $\leq 12$ weeks (first trimester) and $>12$ weeks (second and third trimesters).

The research was approved by the University Committee on Human Subjects, Cornell University.
FIGURE 1. Hemoglobin-altitude curve for women of childbearing age, for 1000 to 4800 meters, 1999

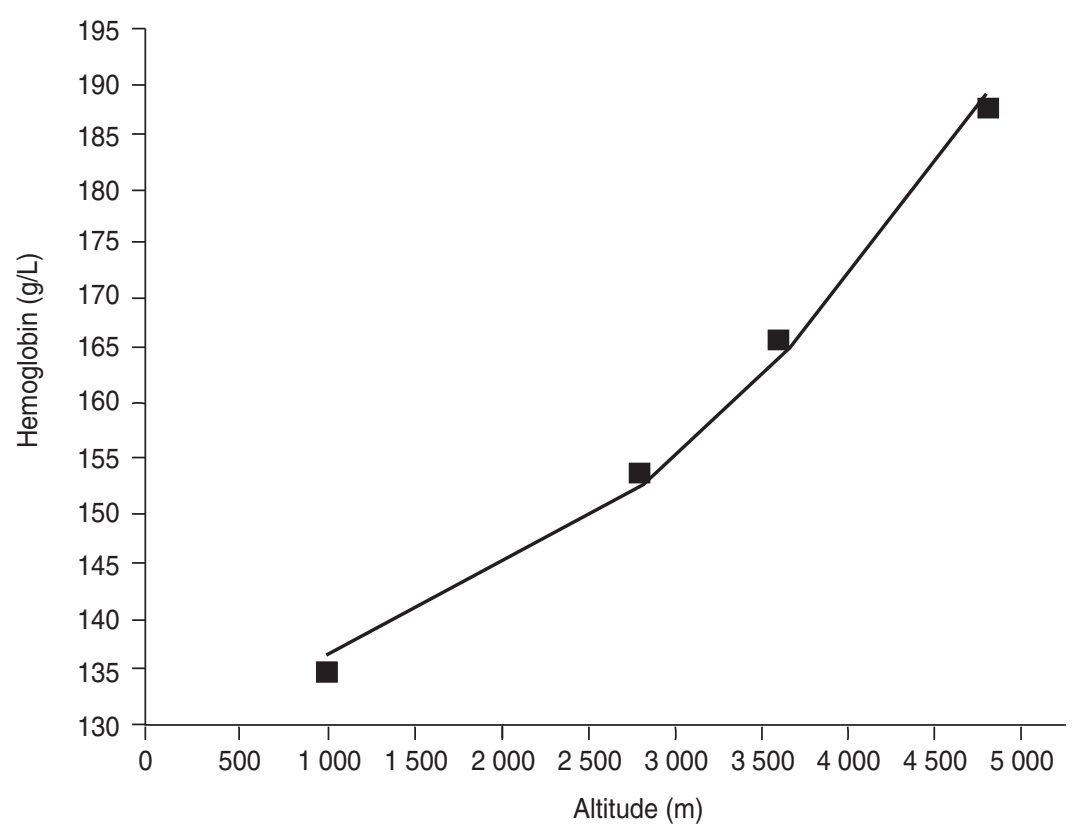

We used the SPSS computer software program (17) for descriptive statistics and correlations between hemoglobin concentration and variables which could potentially confound the relationship with altitude.

We determined hemoglobin cutoffs at $3600 \mathrm{~m}$ (La Paz) and $4000 \mathrm{~m}$ (El Alto) at the 2.5th percentile of the mean derived from our exponential function. We assumed a constant coefficient of variation of 0.061 at each of the altitudes, based on observations from five studies $(7,8,10,15,18)$.

Following the WHO recommendation (4), we adjusted our cutoffs by subtracting $10 \mathrm{~g} / \mathrm{L}$ for the last two trimesters of pregnancy. We compared our estimates of the prevalence of iron deficiency anemia against the estimates generated from the hemoglobin cutoffs derived from the exponential function of Dirren et al. (12) adjusted for the higher hemoglobin concentration of women at sea level, and also against the estimates produced by the method of Dallman et al. (13), which applies a $4 \%$ increase in hemoglobin concentration per $1000 \mathrm{~m}$ of rise in altitude.

\section{RESULTS}

\section{Hemoglobin-altitude exponential curve}

The curve which best fit the hemoglobin-altitude data shown in Table 1 for nonanemic women of childbearing age was:

$$
\begin{aligned}
& \text { Hemoglobin }=120+16.3 \times \\
& {\left[\exp ^{(0.00038 \times(\text { altitude }-1000))}\right]} \\
& \left(\mathrm{R}^{2}=.995, P<.05\right)
\end{aligned}
$$

Figure 1 shows that hemoglobinaltitude curve graphically.

Based on the function predicting hemoglobin concentration from altitude, the mean hemoglobin concentration at $3600 \mathrm{~m}$ for women of childbearing age was $164.2 \mathrm{~g} / \mathrm{L}$. Assuming a constant coefficient of variation, the hemoglobin cutoff at the 2.5 th percentile was $144.6 \mathrm{~g} / \mathrm{L}$. At $4000 \mathrm{~m}$, the predicted mean hemoglobin concentration was $171.0 \mathrm{~g} / \mathrm{L}$, which gave a hemoglobin cutoff of $150.6 \mathrm{~g} / \mathrm{L}$.

Using the correction method of Dallman et al. (13), of $4 \%$ per $1000 \mathrm{~m}$, the 
hemoglobin cutoff determined for $3600 \mathrm{~m}$ was $137.3 \mathrm{~g} / \mathrm{L}$, and for $4000 \mathrm{~m}$ it was $139.2 \mathrm{~g} / \mathrm{L}$.

In the method of Dirren et al., the altitude-appropriate hemoglobin cutoff is determined by taking the difference of the mean hemoglobin concentration predicted from their model for a specific altitude and the mean hemoglobin concentration of a reference nonanemic population at sea level and adding it to the WHO-recommended cutoff of 120 $\mathrm{g} / \mathrm{L}$. The mean hemoglobin concentrations predicted from the model by Dirren et al. for 3600 and $4000 \mathrm{~m}$ were $150.5 \mathrm{~g} / \mathrm{L}$ and $160.2 \mathrm{~g} / \mathrm{L}$, respectively. The reference sea-level hemoglobin concentration used to calculate the cutoffs was $134.8 \mathrm{~g} / \mathrm{L}$; it was derived from a population of nonanemic iron-sufficient women of childbearing age residing at sea level (15). Thus the cutoffs for 3600 and $4000 \mathrm{~m}$ were $135.7 \mathrm{~g} / \mathrm{L}$ and $145.4 \mathrm{~g} / \mathrm{L}$, respectively.

To adjust for plasma volume expansion in pregnancy, all of the hemoglobin cutoffs were reduced by $10 \mathrm{~g} / \mathrm{L}$ to estimate the prevalence of iron deficiency anemia in the combined second and third trimesters of pregnancy (4).

Table 2 compares the pregnancy cutoffs for $3600 \mathrm{~m}$ and for $4000 \mathrm{~m}$ that were derived according to our new approach and the approaches of Dirren et al. (12) and Dallman et al. (13).

\section{Description of the sample used to estimate the prevalence of iron deficiency anemia}

Table 3 shows the characteristics of the sample of women for whom the prevalence of anemia was estimated by the three altitude correction factors. All of the women reported having access to running water and electricity. To be eligible to attend the prenatal clinics either the woman was working or some other member of her immediate family was. In La Paz $23 \%$ of the women first came in for prenatal care, including hemoglobin screening, during the first trimester; in El Alto $28 \%$ of the women did.

In La Paz and El Alto there were significant (alpha $=.05$ ) positive correla-

TABLE 2. Hemoglobin cutoffs $(\mathrm{g} / \mathrm{L})$ for a sample of pregnant women residing at two altitudes in Bolivia, calculated according to three different methods of correcting for altitude, $1999^{\mathrm{a}}$

\begin{tabular}{lccc}
\hline & Dallman et al. & Dirren et al. & This study \\
\hline La Paz $(3600 \mathrm{~m})$ & & & \\
1st trimester & 137.3 & 135.7 & 145.8 \\
2nd and 3rd trimesters & 127.3 & 125.7 & 135.8 \\
El Alto (4 000 m) & & & \\
1st trimester & 139.2 & 145.4 & 150.6 \\
2nd and 3rd trimesters & 129.2 & 135.4 & 140.6 \\
\hline
\end{tabular}

a The cutoffs calculated in this table were based on data on the hemoglobin levels of pregnant women collected in Bolivia during 1995 and 1996.

TABLE 3. Characteristics of the total sample of pregnant women residing at two altitudes in Bolivia, 1995-1996

\begin{tabular}{|c|c|c|c|c|}
\hline & $\begin{array}{l}\text { Mean } \pm \text { standard } \\
\text { deviation }\end{array}$ & Minimum & Maximum & $\begin{array}{l}\text { Sample } \\
\text { size }\end{array}$ \\
\hline \multicolumn{5}{|l|}{ La Paz (3 600 m) } \\
\hline Hemoglobin (g/L) & $137.1 \pm 12.8$ & 68.0 & 170.0 & 202 \\
\hline Age (years) & $26.5 \pm 3.5$ & 18.0 & 35.0 & 202 \\
\hline Height $(\mathrm{cm})$ & $151.5 \pm 5.4$ & 137.0 & 170.0 & 150 \\
\hline Weight (kg) & $62.4 \pm 8.6$ & 42.0 & 96.0 & 195 \\
\hline Income (bolivianos/month) ${ }^{a}$ & $644.3 \pm 451.4$ & 149.0 & 2382.0 & 199 \\
\hline Weeks of gestation ${ }^{b}$ & $20.3 \pm 8.3$ & 2.0 & 38.0 & 201 \\
\hline \multicolumn{5}{|l|}{ El Alto (4 $000 \mathrm{~m})$} \\
\hline Hemoglobin (g/L) & $142.9 \pm 14.2$ & 114.0 & 176.0 & 101 \\
\hline Age (years) & $26.3 \pm 3.8$ & 18.0 & 35.0 & 101 \\
\hline Height $(\mathrm{cm})$ & $150.8 \pm 5.2$ & 141.0 & 168.0 & 81 \\
\hline Weight (kg) & $62.2 \pm 8.4$ & 43.2 & 85.6 & 101 \\
\hline Income (bolivianos/month) ${ }^{\mathrm{a}}$ & $610.6 \pm 417.5$ & 113.0 & 2874.0 & 100 \\
\hline Weeks of gestation ${ }^{b}$ & $18.4 \pm 7.9$ & 6.0 & 39.0 & 100 \\
\hline
\end{tabular}

a Income is for the household; in 1996 the exchange rate was approximately five bolivianos to the United States dollar.

b Weeks of gestation period is for the time at which a woman first came to a prenatal clinic.

tions between hemoglobin concentration and body weight, and negative correlations between hemoglobin concentration and trimester of pregnancy. There was no difference in mean income, education, or parity between those women seeking prenatal care in the first trimester of pregnancy and in the combined second and third trimesters of pregnancy. In La Paz the mean hemoglobin concentration in the first trimester $(146.5 \pm 12.6 \mathrm{~g} / \mathrm{L})$ was significantly higher than that in the combined second and third trimesters $(134.3 \pm 11.5 \mathrm{~g} / \mathrm{L})$ of pregnancy, by $12 \mathrm{~g} / \mathrm{L}$. In El Alto the mean hemoglobin concentration in the first trimester $(150.2 \pm 10.1)$ was significantly higher than that in the combined second and third trimesters $(139.9 \pm 11.9 \mathrm{~g} / \mathrm{L})$ of pregnancy, by $10 \mathrm{~g} / \mathrm{L}$.

Comparison of the three methods for estimating the prevalence of iron deficiency anemia in pregnancy

As compared with the method derived in this study, the methods of Dallman et al. (13) and Dirren et al. (12) indicated lower prevalences of iron deficiency anemia in both the first trimester of pregnancy and in the combined second and third trimester period, in both La Paz and El Alto (Table 4). The estimates by the method of Dirren et al. were similar to those of Dallman et al. for the population residing 
TABLE 4. Estimates of prevalence (with $95 \%$ confidence intervals) for iron deficiency anemia by location and trimester of pregnancy for a sample of pregnant women residing at two altitudes in Bolivia, calculated according to three different models, 1999

\begin{tabular}{lccc}
\hline & Dallman et al. & Dirren et al. & This study \\
\hline La Paz (3 600 m) & & & \\
1st trimester & $18 \%(16,20)$ & $18 \%(16,20)$ & $42 \%(40,44)$ \\
2nd and 3rd trimesters & $14 \%(14,14)$ & $14 \%(14,14)$ & $53 \%(53,53)$ \\
El Alto (4 000 m) & & & \\
1st trimester & $7 \%(5,9)$ & $21 \%(18,24)$ & $50 \%(46,54)$ \\
2nd and 3rd trimesters & $21 \%(20,22)$ & $36 \%(35,37)$ & $63 \%(62,64)$ \\
\hline
\end{tabular}

FIGURE 2. Comparison of the hemoglobin by altitude curves fit to hemoglobin concentration data in children from the study of Dirren et al.

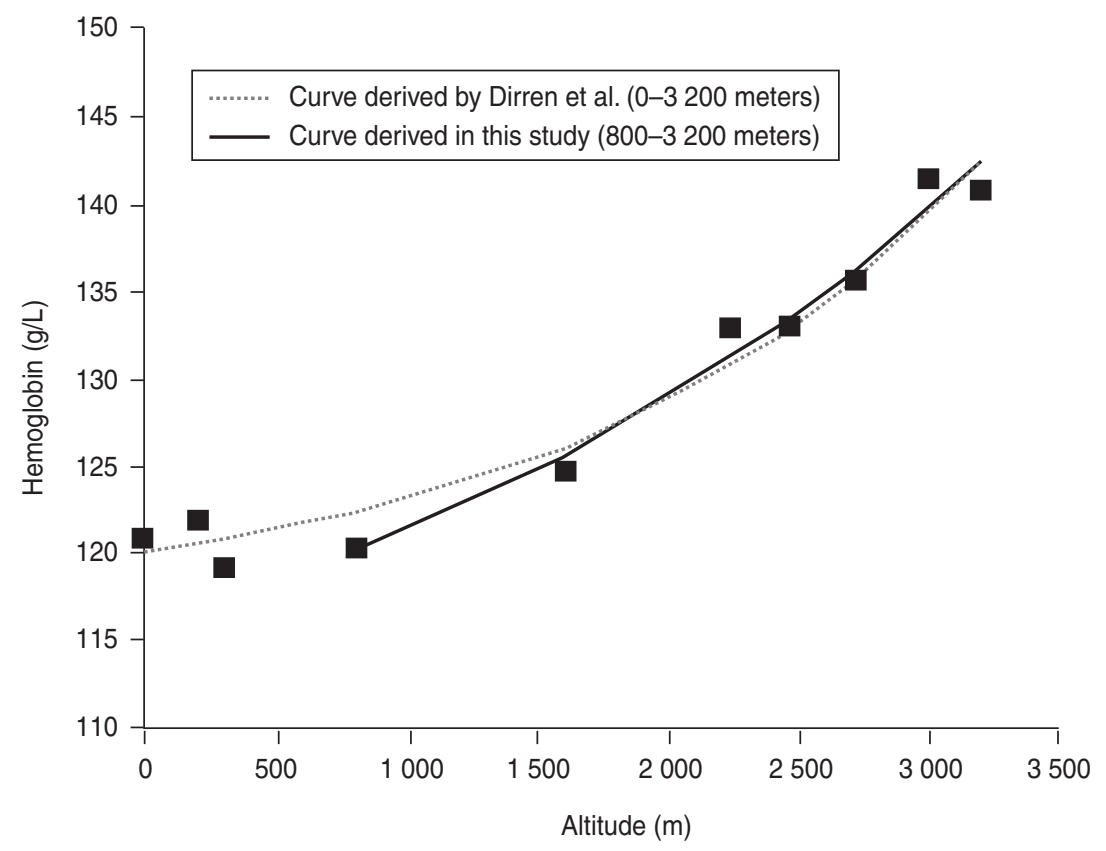

in La Paz (3600 m) but higher than those of Dallman et al. for the population residing in El Alto $(4000 \mathrm{~m})$. All three methods indicated that in El Alto the prevalence of iron deficiency anemia was higher in the combined second and third trimester period than in the first trimester. For La Paz, however, only the method derived in this study showed that pattern.

\section{DISCUSSION}

Using three different altitude correction procedures, we estimated the prevalence of iron deficiency anemia due to their assumption that the relationship between hemoglobin concentration and altitude is exponential from sea level, as shown here:

$$
\begin{gathered}
\text { Hemoglobin }=3.44 \times \\
{\left[\exp ^{(0.000633 \times \text { altitude })}\right]+116.9}
\end{gathered}
$$

A visual inspection of the curve which Dirren et al. used to fit the hemoglobin and altitude data reveals that it is probably not the best fitting curve (Figure 2).

We also compared the hemoglobinaltitude curve for women of childbearing age derived in this study to that of Dirren et al. in children by comparing the fit of both of the curves to the data of women of childbearing age. The curve of Dirren et al. was modified to account for the higher hemoglobin concentration of women at sea level. The $\mathrm{R}^{2}$ of the curve of Dirren et al. applied to the data of women of childbearing age was .896, as compared to an $\mathrm{R}^{2}$ of .995 for the curve derived in this study and shown in Figure 1.

The hemoglobin-altitude curve determined by Dirren et al. underestimates the slope of the relationship. As a result, as altitude increases so does the underestimation of prevalence of iron deficiency anemia using the hemoglobin cutoffs derived from their curve.

With the method of Dallman et al. the lower estimates of prevalence are consistent with their lower hemoglobin cutoffs, which are based on an assumed linear relationship between hemoglobin concentration and altitude (13). However, since the relationship between hemoglobin concentration and altitude has been shown to be of an exponential nature, the adjustment factor used by Dallman et al. does not seem to be appropriate and would have the tendency to consistently underestimate the prevalence of iron deficiency anemia at high altitude.

We derived an exponential curve of hemoglobin concentration by altitude which was theoretically grounded on the nonlinear shape of the oxygen disassociation curve. When we adjusted our curve for the lower hemoglobin concentration of children and then looked at the portion of the data from 
Dirren et al. that was on children above $800 \mathrm{~m}$, our new curve provided a better fit $\left(\mathrm{R}^{2}=.995, P<.05\right)$ than did the curve they had earlier proposed $\left(\mathrm{R}^{2}=.965, P<.001\right)$ (Figure 2$)$.

Haas (10) estimated the mean hemoglobin concentration of healthy noniron-deficient nonpregnant women residing in La Paz to be $163.0 \mathrm{~g} / \mathrm{L}$. That figure was similar to the after-supplementation mean hemoglobin concentration of $165.6 \mathrm{~g} / \mathrm{L}$ observed by Berger et al. (8) for women of childbearing age residing in Atocha, Bolivia, which is at the same altitude as La Paz. This similarity between studies also lends support to the validity of our curve.

We made certain assumptions in estimating the prevalence of iron deficiency anemia in the population of women who gave birth at the hospital in La Paz. The first assumption was that the hemoglobin-by-altitude exponential curve was valid. To assure that the new curve was based on women who were not anemic, we used data from trials on hemoglobin response to iron treatment, and we verified the estimates of anemia with other data.

The second assumption we made was that the coefficient of variation of hemoglobin concentration is constant across altitudes. There is evidence from trials on hemoglobin response to iron treatment and from other studies that supports the assumption of a constant coefficient of variation $(7,8,10,15,18)$. The coefficient of variation provides a measure of relative rather than absolute variation. That seems more appropriate since there is evidence from iron supplementation trials that the standard deviation is not constant across altitudes (5-8). A recalculation of the prevalence of iron deficiency anemia in pregnancy using a constant standard deviation reduced the between-trimester differences in prevalence in both El Alto and La Paz, as well as the differences in estimates between the two cities.

The third assumption we made was that the magnitude of plasma volume expansion in pregnancy at high altitude is similar to that at sea level. There is some circumstantial evidence that this may not be the case $(10,11)$. Haas (10) provided support for larger plasma volume expansion at higher altitudes by showing the differences in mean hemoglobin concentration of non-irondeficient Bolivian women in pregnancy and nonpregnancy was larger $(24 \mathrm{~g} / \mathrm{L})$ at $3600 \mathrm{~m}$ than at sea level $(13 \mathrm{~g} / \mathrm{L})$. However, Zamudio et al. (11) hypothesized that women living in the state of Colorado, in the United States, increase oxygen-carrying capacity at high altitude through hemoconcentration rather than through an increase in red cell mass, resulting in a lowered plasma volume. In a study of hemoglobin response to iron treatment in the 28th week of pregnancy in Ecuadorian women residing in Quito $(2800 \mathrm{~m})$, Freire (19) reported the mean hemoglobin concentration of the iron-repleted group to be $137.6 \mathrm{~g} / \mathrm{L}$. The difference between the mean hemoglobin concentration in pregnancy reported by Freire and the mean hemoglobin concentration in nonpregnant women reported by Yepez et al. (7) in the same location was $15.4 \mathrm{~g} / \mathrm{L}$. This difference is higher than what Haas reported for sea level but lower than what he reported for $3600 \mathrm{~m}$. If the magnitude of plasma volume expansion were different (greater) at high altitude than at sea level, the hemoglobin cutoffs would be lower, and we would have overestimated the prevalence of iron deficiency anemia in the last two-thirds of pregnancy. However, until this greater expansion at high altitude can be confirmed, we recommend using the sea-level adjustment for pregnancy.

We made a fourth assumption in order to compare the prevalence of iron deficiency anemia between trimesters of pregnancy. Since our study was not longitudinal, the comparison assumed that there were no differences between women seeking prenatal care in the first trimester and in the last two trimesters of pregnancy. We verified this by looking at correlations between factors which may be related to the time at which a woman seeks prenatal care.

We did not assume that the population of women delivering at the hospital in La Paz was representative of the general populations of that city and of El Alto. Given the access that the sample population had to the quality pre- natal care at the clinics, the prevalence estimates for those women would tend to be lower than those of the larger populations of $\mathrm{La} \mathrm{Paz}$ and El Alto women who do not have such access.

If rapid assessments are to be carried out for programmatic and policy decisions, further research needs to be done to establish appropriate hemoglobin cutoffs in pregnancy across different altitudes. This is especially true in countries with large populations living at various altitudes above $1000 \mathrm{~m}$. Bolivia, for example, has over six million inhabitants living above $1000 \mathrm{~m} \mathrm{(8)}$.

Given the unknown relationship between plasma volume expansion and altitude, we could not compare the prevalences across populations in $\mathrm{La}$ Paz (3 $600 \mathrm{~m})$ and El Alto $(4000 \mathrm{~m})$ in the second and third trimesters of pregnancy. The best test to confirm the hemoglobin cutoffs would be to measure the iron status of the populations. Until the cutoffs have been confirmed, the hemoglobin correction factors derived in this study can be used to estimate the prevalence of iron deficiency anemia in pregnancy at single altitudes or to compare rates of iron deficiency anemia in nonpregnant women of childbearing age across altitudes so as to target interventions that increase women's iron stores going into pregnancy (9).

\section{Revised cutoffs for anemia at various altitudes}

Table 5 gives hemoglobin cutoffs based on the curve fit in this study between 1000 and $4800 \mathrm{~m}$, in 100-m intervals. These cutoffs can be used to estimate the prevalence of iron deficiency anemia in populations of nonpregnant women residing at the appropriate altitude. They can also be adjusted for women beyond the first trimester of pregnancy by subtracting $10 \mathrm{~g} / \mathrm{L}$. More precise hemoglobin cutoffs can be calculated by using the desired altitude in our model for predicting hemoglobin concentration:

Mean hemoglobin $(\mathrm{g} / \mathrm{L})=$ $120+16.3 \times\left[\exp ^{(0.00038 \times(\text { altitude-1000)) }}\right]$ 
TABLE 5. Hemoglobin cutoffs for women of childbearing age at 100-meter intervals between 1000 and 4800 meters based on the model derived in this study, 1999

\begin{tabular}{cccc}
\hline $\begin{array}{c}\text { Altitude } \\
(\mathrm{m})\end{array}$ & $\begin{array}{c}\text { Hemoglobin } \\
\text { cutoff }(\mathrm{g} / \mathrm{L})\end{array}$ & $\begin{array}{c}\text { Altitude } \\
(\mathrm{m})\end{array}$ & $\begin{array}{c}\text { Hemoglobin } \\
\text { cutoff }(\mathrm{g} / \mathrm{L})\end{array}$ \\
\hline 1000 & 120.0 & 3000 & 136.5 \\
1100 & 120.5 & 3100 & 137.5 \\
1200 & 121.2 & 3200 & 138.8 \\
1300 & 121.8 & 3300 & 140.0 \\
1400 & 122.4 & 3400 & 141.4 \\
1500 & 123.0 & 3500 & 142.7 \\
1600 & 123.7 & 3600 & 144.2 \\
1700 & 124.4 & 3700 & 145.7 \\
1800 & 125.1 & 3800 & 147.2 \\
1900 & 125.8 & 3900 & 148.9 \\
2000 & 126.6 & 4000 & 150.6 \\
2100 & 127.5 & 4100 & 152.3 \\
2200 & 128.3 & 4200 & 154.1 \\
2300 & 129.2 & 4300 & 155.9 \\
2400 & 130.0 & 4400 & 157.9 \\
2500 & 131.0 & 4500 & 159.9 \\
2600 & 132.0 & 4600 & 162.0 \\
2700 & 133.0 & 4700 & 164.2 \\
2800 & 134.1 & 4800 & 166.5 \\
2900 & 135.2 & & \\
\hline
\end{tabular}

The assumed coefficient of variation of 0.061 is then used to calculate the hemoglobin cutoff at the 2.5 th percentile of normal. Using the results from the mean-hemoglobin equation above, the hemoglobin cutoff is calculated as follows:

$$
\begin{gathered}
\text { Hb cutoff }=\text { Mean } \mathrm{Hb}- \\
{[(0.061 \times \text { Mean } \mathrm{Hb}) \times 1.96]}
\end{gathered}
$$

For example, at $4000 \mathrm{~m}$ this model predicts the mean hemoglobin concentration for nonpregnant women is $171.0 \mathrm{~g} / \mathrm{L}$. Using the second equation, the resulting cutoff is $150.6 \mathrm{~g} / \mathrm{L}$. To determine the cutoff for the second and third trimesters of pregnancy, subtract $10 \mathrm{~g} / \mathrm{L}$ from that cutoff, giving a pregnancy cutoff of $140.6 \mathrm{~g} / \mathrm{L}$ at $4000 \mathrm{~m}$.

Acknowledgements. The authors would like to thank Dr. Roberto Bohrt of the Hospital Maternidad 18 de Mayo in La Paz, Bolivia, for providing access to the hospital records. The authors would also like to acknowledge the assistance of Dr. Edward A. Frongillo of the Division of Nutritional Sciences, Cornell University. This research was supported in part by four units at Cornell University: the Program in International Nutrition, the Latin American Studies Program, the Einaudi Center for International Studies, and the Cornell International Institute for Food, Agriculture, and Development. Support also came from U.S. National Institutes of Health training grant DK07158-22.

\section{REFERENCES}

1. United Nations, Administrative Committee on Coordination, Sub-Committee on Nutrition. Third report on the world nutrition situation. Geneva: ACC/SCN; 1997.

2. DeMaeyer E, Adiels-Tegman M. The prevalence of anemia in the world. World Health Stat Q 1985;38(3):302-316.

3. World Bank. World development report. New York: Oxford University Press; 1993.

4. Institute of Medicine. Nutrition during pregnancy. Washington, DC: National Academy Press; 1990.

5. Freire WB. Strategies of the Pan American Health Organization for the control of iron deficiency in Latin America. Nutr Rev 1997; 55(6):183-188.

6. Garby L, Irnell L, Werner I. Iron deficiency in women of fertile age in a Swedish community. III. Estimation of prevalence based on response to iron supplementation. Acta Med Scand 1969;185:113-117.

7. Yepez R, Estevez E, Galan P, et al. Anémie en altitude: validité du critère de définition. Santé 1994;4(1):9-13.

8. Berger J, Aguayo VM, San Miguel JL, Lujan C, Tellez W, Traissac P. Definition and preva- lence of anemia in Bolivian women of childbearing age living at high altitudes: the effect of iron-folate supplementation. Nutr Rev 1997; $55: 247-256$.

9. U.S. Centers for Disease Control and Prevention. Recommendations to prevent and control iron deficiency in the United States. MMWR 1998;47(RR-3):1-36.

10. Haas J. Distribución de la hemoglobina en individuos normales residentes a gran altitud en Bolivia. In: Berger J, ed. Anemia por deficiencia de hierro en la región andina: definición y estrategias de intervención. La Paz, Bolivia: Institut Français de Recherche Scientifique pour le Développement en Coopération; 1996. p. 55-77.

11. Zamudio S, Palmer SK, Dahms TE, Berman JC, Young DA, Moore LG. Alterations in uteroplacental blood flow precede hypertension in preeclampsia at high altitude. J Appl Physiol 1995:79(1):15-22.

12. Dirren H, Logman MHGM, Barclay DV, Freire WB. Altitude correction for hemoglobin. Eur J Clin Nutr 1994;48(9):625-632.

13. Dallman PR, Siimes MA, Steckel A. Iron deficiency in infancy and childhood. Am J Clin Nutr 1980;33(1):86-118.
14. Hurtado A, Merino C, Delgado E. Influence of anoxemia on the hemopoietic activity. Arch Int Med 1945;75:284-323.

15. Looker AC, Dallman PR, Carroll MD, Gunter EW, Johnson CL. Prevalence of iron deficiency in the United States. JAMA 1997; 277(12):973-976.

16. Microcal Software, Inc. Origin 5.0. Northhampton, MA: Microcal Software, Inc.; 1991-1997.

17. SPSS. SPSS Version 7.1. Chicago, Illinois: SPSS Inc.; 1996.

18. Cook J, Alvarado J, Gutnisky A, Jamra M, Labardini J, Layrisse M, et al. Nutritional deficiency and anemia in Latin America: a collaborative study. Blood 1971;38:591-603.

19. Freire WB. Hemoglobin as a predictor of response to iron therapy and its use in screening and prevalence estimates. Am J Clin Nutr 1989;50(6):1442-1449.

Manuscript received on 8 February 1999. Revised version accepted for publication on 27 August 1999. 
RESUMEN Los dos objetivos principales de este estudio consistieron en: 1) establecer un método para determinar valores de corte de la concentración de hemoglobina que permitan estimar mejor la prevalencia de la anemia ferropénica en embarazadas residentes a

Factores de corrección de los niveles de hemoglobina para estimar la prevalencia de la anemia ferropénica en mujeres residentes a gran altitud en Bolivia gran altitud, y 2) estimar la prevalencia de la anemia en una muestra de embarazadas residentes en dos ciudades de Bolivia: La Paz (3 600 m) y El Alto (4 000 m). El método utilizado por nosotros se basó en datos ya publicados acerca de las concentraciones medias de hemoglobina en mujeres no anémicas en edad fértil residentes a diferentes altitudes, a partir de los cuales derivamos una curva de hemoglobina-altitud. Este modelo se comparó con otros dos publicados anteriormente y utilizados en la actualidad, cuyos valores de corte habían sido derivados de poblaciones de niños u hombres residentes a menos de $4000 \mathrm{~m}$ y extrapolados posteriormente a las mujeres y a mayores altitudes. A partir de las historias clínicas de mujeres de La Paz y El Alto que habían dado a luz en un hospital maternal de La Paz entre enero y junio de 1996, se extrajeron los datos sobre sus concentraciones de hemoglobina, a los cuales se aplicaron los tres modelos para calcular la prevalencia de la anemia ferropénica en esta población.

La curva de hemoglobina-altitud derivada en este estudio se ajustó mejor a los datos de las mujeres en edad fértil que cualquiera de los otros dos modelos. Utilizando los valores de corte de los niveles de hemoglobina determinados en este estudio, la prevalencia estimada de la anemia ferropénica en el embarazo fue mayor que las prevalencias estimadas con los otros dos métodos. 